\title{
AVALIAÇÃO DA ATIVIDADE INSETICIDA DE EXTRATOS VEGETAIS SOBRE Spodoptera eridania (CRAMER) (LEPIDOPTERA: NOCTUIDAE)
}

\author{
José Romário de Carvalho ${ }^{1}$ \\ lana Pedro da Silva Quadros ${ }^{2}$ \\ Chansislayne Gabriela da Silva ${ }^{3}$ \\ Fernanda de Paula Roldi Vieira ${ }^{4}$ \\ Milena Fazolo ${ }^{5}$ \\ Vagner Tebaldi de Queiroz ${ }^{6}$ \\ Adilson Vidal Costa ${ }^{7}$ \\ Dirceu Pratissoli ${ }^{8}$
}

Resumo: Spodoptera eridania é uma espécie desfolhadora cuja fase larval se alimenta de várias espécies de importância econômica. Dada a grande participação do agronegócio na economia do país e compreendendo a necessidade de buscar métodos que viabilizem o controle de pragas de maneira sustentável e segura para o meio ambiente, o uso de extratos vegetais com potencial inseticida pode oferecer uma alternativa de baixo custo e de fácil produção. Sendo assim, objetivou-se com este estudo avaliar a atividade inseticida de plantas sobre a mortalidade de larvas de S. eridania. Para isto, utilizou-se extratos aquosos de fumo (N. tabacum L.), cinamomo (M. azedarach), alho (A. sativum L.), pimenta roxa (C. chinense) e erva-de-santa-maria (C. ambrosioides L.), os quais foram pulverizados sobre lagartas de segundo instar de S. eridania e sobre o alimento fornecido. O extrato de Fumo apresentou-se promissor para o controle de S. eridania, sendo necessárias novas pesquisas que possibilitem verificar concentrações que ocasionem mortalidade acima de 50\%, bem como testes de fitotoxidade do extrato na planta hospedeira.

Palavras-chave: Extratos, Inseticida, Lagarta, Spodoptera eridania.

\footnotetext{
${ }^{1}$ Doutorando/Universidade Federal do Espírito Santo, Brasil. E-mail: jromario_carvalho@hotmail.com.

2 Mestranda/Universidade Federal do Espírito Santo, Brasil. E-mail: ianaquadros@gmail.com.

${ }^{3}$ Agronomia/Universidade Federal do Espírito Santo, Brasil. E-mail: chansislayne_silva@outlook.com.

${ }^{4}$ Mestranda/Universidade Federal do Espírito Santo, Brasil. E-mail: fernandaroldi@hotmail.com.

${ }^{5}$ Química Licenciatura/Universidade Federal do Espírito Santo, Brasil. E-mail: fazolomilena@gmail.com.

${ }^{6}$ Pesquisador/Universidade Federal do Espírito Santo, Brasil. E-mail: vagnertq@gmail.com.

7 Pesquisador/Universidade Federal do Espírito Santo, Brasil. E-mail: avcosta@hotmail.com.

8 Pesquisador/Universidade Federal do Espírito Santo, Brasil. E-mail: dirceu.pratissoli@gmail.com.
} 